\title{
Screening Of Plastic Degrading Bacteria from Dumped Soil Area
}

\author{
Omar Saad Jumaah \\ Directorate General of Education of Anbar, Ministry of Education, Iraq
}

\begin{abstract}
Plastic wastes accumulating in the environment are posing an ever increasing ecological threat. Plastics that are biodegradable can be considered environment friendly, they have an increasing range of potential application and are driven by the growing use of plastics in packaging. In this study, the biodegradation of plastic material was analyzed 1 month of incubation in liquid culture method. The microbial species found associated with the degrading materials were identified as three Gram positive and two Gram negative bacteria. The microbial species associated with the polythene materials were identified as Bacillus amylolyticus, Bacillus firmus, Pseudomonas putida, Pseudomonas fluroscence, Bacillus subtilis. The efficacy of microbes in the degradation of plastics were analyzed in liquid (shaker) culture method, among the bacteria Pseudomonas putida degrades plastic more in 1 month (30\% weight loss/month) period compared to others and lowest degradation rate was observed in case of Bacillus subtilis (22\% weight loss/month). This work reveals that Pseudomonas putida posses greater potential to degrade plastics when compared with other bacteria.
\end{abstract}

Key words: Biodegradation, plastics, bacterial species, FTIR.

\section{Introduction}

Plastic is the most useful synthetic 'manmade' substance, made up of elements extracted from the fossil fuel resources. It has made possible most of the industrial and technological revolutions of the 19th and 20th centuries. During the past 30 years plastic materials such as polyethylene (LDPE, MDPE, HDPE, LLDPE), polypropylene (PP), polystyrene (PS), polyvinyl chloride (PVC), polyurethane (PUR), polybutylene terephthalate (PBT), nylons have been used widely in food, clothing, shelter, transportation, construction, medical and leisure industries because they are lightweight, low cost, extremely durable and relatively unbreakable (Kumar et al., 2007).

A very general estimate of worldwide plastic waste generation is annually about 57 million tons (Bollag et al., 2000). They do not break down in the environment easily because they are resistant to microbial attack, due to their excessive molecular mass, high number of aromatic rings, unusual bonds, or halogen substitutions (Alexander, 1981). As a result they remain in the environment for a very long time without any deterioration and the large-scale accumulation of waste plastics in the biosphere has given rise to the problem of severe environmental pollution These problems have made plastic waste a major focus in the management of solid waste. Due to plastic's resilience against degradation and its proliferation in industry, the issue of plastic pollution has evolved to become a threat to global ecology (Kim and Rhee, 2003)..

Low density polyethylene is one of the major sources of environmental pollution. Polyethylene is a polymer made of long chain monomers of ethylene. The worldwide utility of polyethylene is expanding at a rate of $12 \%$ annum and approximately 140 million tones of synthetic polymers are produced worldwide each year. With such huge amount of polyethylene getting accumulated in the environment, their disposal evokes a big ecological issue. It takes thousand years for their efficient degradation. Since polymers are extremely stable, their degradation cycles in the biosphere are limited. In Western Europe alone it is estimated that $7.4 \%$ of municipal solid waste are plastic, which are classified as $65 \%$ polyethylene/polypropylene, $15 \%$ polystyrene, $10 \%$ PVC, $5 \%$ polyethylene terephthalate and remaining others (Shimao, 2001).

Environmental pollution by synthetic polymers, such as waste plastics and water-soluble synthetic polymers in waste- $\quad$ water has been recognized as a major problem. In view of this, energetic, chemical and biological polymer-degrading techniques have been studied extensively during the last three decades. The energetic agencies can be either thermal or radiant. The radiant energy may be high-energy radiation like gamma rays, ion beams, and electrons or even low energy radiation like ultra-violet (UV) rays. Chemical degradation is caused using certain chemicals like acids and alkalis, etc. Usage of certain microorganisms and enzymes to degrade polymers are classified as the biodegradation method of polymers (Premraj and Doble, 2005).

The microbial species are associated with the degrading materials. Microbial degradation of plastics is caused by certain enzymatic activities that lead to a chain cleavage of the polymer into oligomers and monomers. These water soluble enzymatically cleaved products are further absorbed by the microbial cells where they are metabolized. Aerobic metabolism results in carbon dioxide and water (Starnecker and Menner, 1996), and anaerobic metabolism results in the production of carbon dioxide, water and methane and 
are called end products, respectively ( $\mathrm{Gu}$ et al., 2000). The degradation leads to breaking down of polymers to monomers creating an ease of accumulation by the microbial cells for further degradation.

Microorganisms can degrade plastic over 90 genera, from bacteria and fungi, among them; Bacillus megaterium, Pseudomonas sp., Azotobacter, Ralstonia eutropha, Halomonas sp., etc. (Chee et al., 2010). Plastic degradation by microbes due to the activity of certain enzymes that cause cleavage of the polymer chains into monomers and oligomers. Plastic that has been enzymatically broken down further absorbed by the microbial cells to be metabolized. Aerobic metabolism produces carbon dioxide and water. Instead of anaerobic metabolism produces carbon dioxide, water, and methane as end products (Usha et al., 2011).

The purpose of this study was to isolate microorganism from dumped soil area and screening of the potential plastic degrading microorganisms and indentifying the high potential microorganism that degrade the plastics.

\section{Sample collection}

\section{Materials And Methods}

The soil sample (Municipal solid waste, where plastic bags were buried) was obtained from a compost plant, Municipal Corporation, Aurangabad, India. The compost inoculum was free from larger inert materials (glass, stones, metals, etc.) as much as possible. These items are removed manually as much as possible to produce a homogenous compost inoculum. The soil sample had the following basic properties: total solids (\% TS) $81 \%$; volatile solids at $550^{\circ} \mathrm{C}(\% \mathrm{VS}) 18 \%, \mathrm{pH} 7.2, \mathrm{C} / \mathrm{N}$ ratio 15.3 . It was used for isolation of polymer degrading microorganisms.

Plastic Material: Commonly available plastic bags were collected from Solid waste plant of Municipal Corporation, Aurangabad

\section{Media for cultivation and degradation experiments}

Nutrient broth and Nutrient agar were obtained from HIMEDIA Laboratories Ltd. Minimal synthetic media includes $\left(\mathrm{NH}_{4} \mathrm{NO}_{3}(1.0 \mathrm{~g} / \mathrm{l}), \mathrm{MgSO}_{4} .7 \mathrm{H} 20(0.2 \mathrm{~g} / \mathrm{l}), \mathrm{K}_{2} \mathrm{HPO}_{4}(1.0 \mathrm{~g} / \mathrm{l}), \mathrm{CaCl}_{2} .2 \mathrm{H}_{2} \mathrm{O}(0.1 \mathrm{~g} / \mathrm{l}), \mathrm{KCl}(0.15\right.$ $\mathrm{g} / \mathrm{l})$, Yeast extract $(0.1 \mathrm{~g} / \mathrm{l}), \mathrm{FeSO}_{4} \cdot 6 \mathrm{H}_{2} \mathrm{O}(1.0 \mathrm{mg} / \mathrm{l}), \mathrm{ZnSO}_{4} .7 \mathrm{H}_{2} \mathrm{O}(1.0 \mathrm{mg} / \mathrm{l}), \mathrm{MnSO}_{4}(1.0 \mathrm{mg} / \mathrm{l})$ devoid of any carbon source was used for degradation experiments. Media sterilization was performed by autoclaving at $121^{\circ} \mathrm{C}$ and $15 \mathrm{lbs}$ pressure for 15 minutes.

\section{Isolation of polymer degrading microorganisms:}

The plastic degrading microorganisms were isolated from soil with the help of serial dilution.

Total heterotrophic count:

C.F.U. /g= Number of colonies/ inoculums size (ml) $\mathrm{X}$ dilution factor

\section{Bacterial isolation and identification:}

The bacterial strains isolated with the ability to degrade and performed on the basis of macroscopic and microscopic examination and biochemical test. The bacterial isolates were identified macroscopically by examining colony by examining colony morphology, surface pigment, size shape, margin, surface on media plates and microscopic examination including, grams staining to study the staining behavior, shape, and cell arrangement and granulation, spore staining. The motility test was also per performed biochemical test. The isolates were identified by using selective medium (Kandler and Weiss, 1986).

\section{Microbial Degradation of Plastics in Laboratory Condition: Determination of Weight Loss:}

Pre-weighed discs of 1-cm diameter prepared from polythene bags were aseptically transferred to the conical flask containing $50 \mathrm{ml}$ of culture broth medium, inoculated with different bacterial species. Control was maintained with plastic discs in the microbe-free medium. Different flasks were maintained for each treatment and left in a shaker. After one month of shaking, the plastic discs were collected, washed thoroughly using distilled water, shade-dried and then weighed for final weight. From the data collected, weight loss of the plastics was calculated.

\section{Fourier Transform Infrared (FTIR) and Attenuated Total Reflectance (ATR) spectroscopy}

FTIR analysis is a useful tool to determine the formation of new or disappearance of functional groups. So degradation products, chemical moieties incorporated into the polymer molecules such as branches, comonomers, unsaturation and presence of additives such as antioxidants can be determined by this technique. Fourier transform-attenuated total reflectance (FT-ATR) infrared spectroscopic studies were carried out on plastic samples using a Shimadzu in the horizontal ATR mode, using a zinc-selenide crystal. A total of 3 scans were taken. 


\section{Results And Discussion}

The present study deals with the isolation, identification, and ability of plastic degrading microorganisms from soil. Different types of changes are produced by the microorganism during biochemical analysis. These bacterial strains were isolated and characterized through macroscopic and microscopic studies. Biodegradation of polymer was measured by weight loss in the polymer and FTIR spectroscopy. Thus, the duration of the microbial colonization is an important factor that effect period.

Table No. 1: Colony morphology of the bacterial strain on the basis of serial dilution.

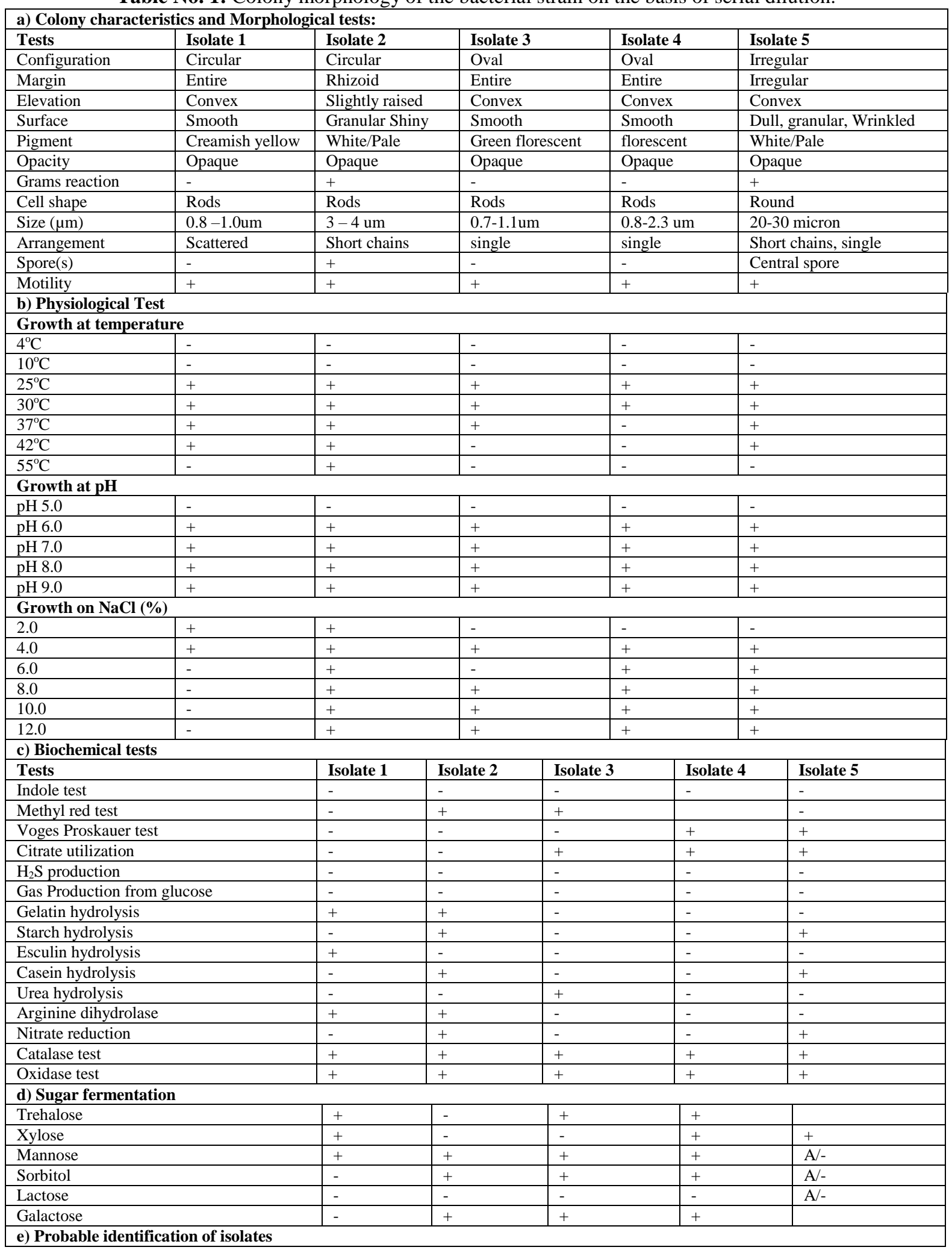




\begin{tabular}{|c|l|l|}
\hline Sr. No. & Isolates & Identified isolate \\
\hline 1. & Isolate 1 & Bacillus amylolyticus \\
\hline 2. & Isolate 2 & Bacillus firmus \\
\hline 3. & Isolate 3 & Pseudomonas putida \\
\hline 4. & Isolate 4 & Pseudomonas fluroscence \\
\hline 5. & Isolate 5 & Bacillus subtilis \\
\hline
\end{tabular}

The bacterial strains isolated with the ability to degrade and performed on the basis of macroscopic and microscopic examination and biochemical test. The bacterial isolates were identified macroscopically by examining colony characteristics, pigment, size shape, margin, and microscopic examination including, grams staining to study the staining behavior, shape, and cell arrangement and granulation, spore staining, motility test was also per performed biochemical test.

A total of 5 isolates were isolated from dumped soil of Municipal Corporation of Aurangabad. Theses 5 isolates were purified in order to tilt to the next test and screened for plastic degradation by incubation for 1 month in an incubator shaker at $130 \mathrm{rpm}$ agitation in a $37^{\circ} \mathrm{C}$ temperature conditions. The bacteria which were identified from the above biochemical tests are Bacillus amylolyticus, Bacillus firmus, Pseudomonas putida, Pseudomonas fluroscence, Bacillus subtilis by the software PIBWIN (Probabilistic identification of bacteria). Degradation of Polyethylene Plastic Waste was carried out (Kathiresan, 2003). Weigh polyethylene plastic (initial weight) and then washed with sterile distilled water and sprayed with $70 \%$ alcohol. Plastic is inserted into the $100 \mathrm{~mL}$ erlenmeyer containing NB and TSB media as much as $50 \mathrm{~mL}$ aseptically. So as much as 2 loops inoculated bacterial isolates to the media. Then incubated in an incubator shaker at room temperature, with agitation of $130 \mathrm{rpm}$ for a month. Polyethylene plastic that has been incubated for a month, washed with sterile distilled water and then sprayed with alcohol dried aired then weighed (final weight). Determination of the percentage of degradation of polyethylene plastic by bacteria by using following formula:

$$
\% \text { Degradation }=\quad \frac{\text { Final weight }}{\text { Initial weight }} \times 100 \%
$$

Table No. 1: Result of degradation of plastic sample by bacteria

\begin{tabular}{|l|l|l|l|l|l|}
\hline $\begin{array}{l}\text { Isolates } \\
\text { no. }\end{array}$ & Name of bacteria & $\begin{array}{l}\text { Initial wt } \\
(\mathbf{m g})\end{array}$ & $\begin{array}{l}\text { Final wt } \\
(\mathbf{m g})\end{array}$ & Difference & $\begin{array}{l}\text { Weight } \\
\text { Loss/month (in \%) }\end{array}$ \\
\hline 1 & Bacillus amylolyticus & 50 & 40 & 10 & 20 \\
\hline 2 & Bacillus firmus & 50 & 44 & 06 & 12 \\
\hline 3 & Pseudomonas putida & 50 & 35 & 15 & 30 \\
\hline 4 & Pseudomonas fluroscence & 50 & 42 & 08 & 16 \\
\hline 5 & Bacillus subtilis & 50 & 39 & 11 & 22 \\
\hline
\end{tabular}

\section{Microbial degradation of plastics under laboratory conditions:}

To assess this, the pre-weighed discs of 1-cm diameter prepared from polythene bags were aseptically transferred to the conical flask containing $50 \mathrm{ml}$ of culture broth medium, inoculated with different bacterial species separately. Control was maintained with plastic discs in the microbe-free medium. Five flasks were maintained for each treatment and left in a shaker. After one month of shaking, the plastic discs were collected, washed thoroughly using distilled water, shade-dried and then weighed for final weight. From the data collected, weight loss of the polythene bag was calculated. The species tested were Bacillus amylolyticus, Bacillus firmus, Pseudomonas putida, Pseudomonas fluroscence and Bacillus subtilis. Among the bacteria, Pseudomonas putida and Bacillus subtilis were found most active in degrading $30 \%$, and $22 \%$ of polythene respectively in one month period.

\section{FTIR spectra of BOPP film before and after degradation in compost and in media}

Fourier Transform Infrared Spectroscopy analysis was used for detecting the formation of new functional groups or changes in the amount of existing functional groups (Milstein et al., 1994).

FTIR spectra of plastic material. Figure 1 and 2 and 3 shows the FTIR spectra of plastic material after degradation by isolated bacterial strain. The overlapping spectra in the expanded form are also provided for comparison, which clearly depict the changes observed 

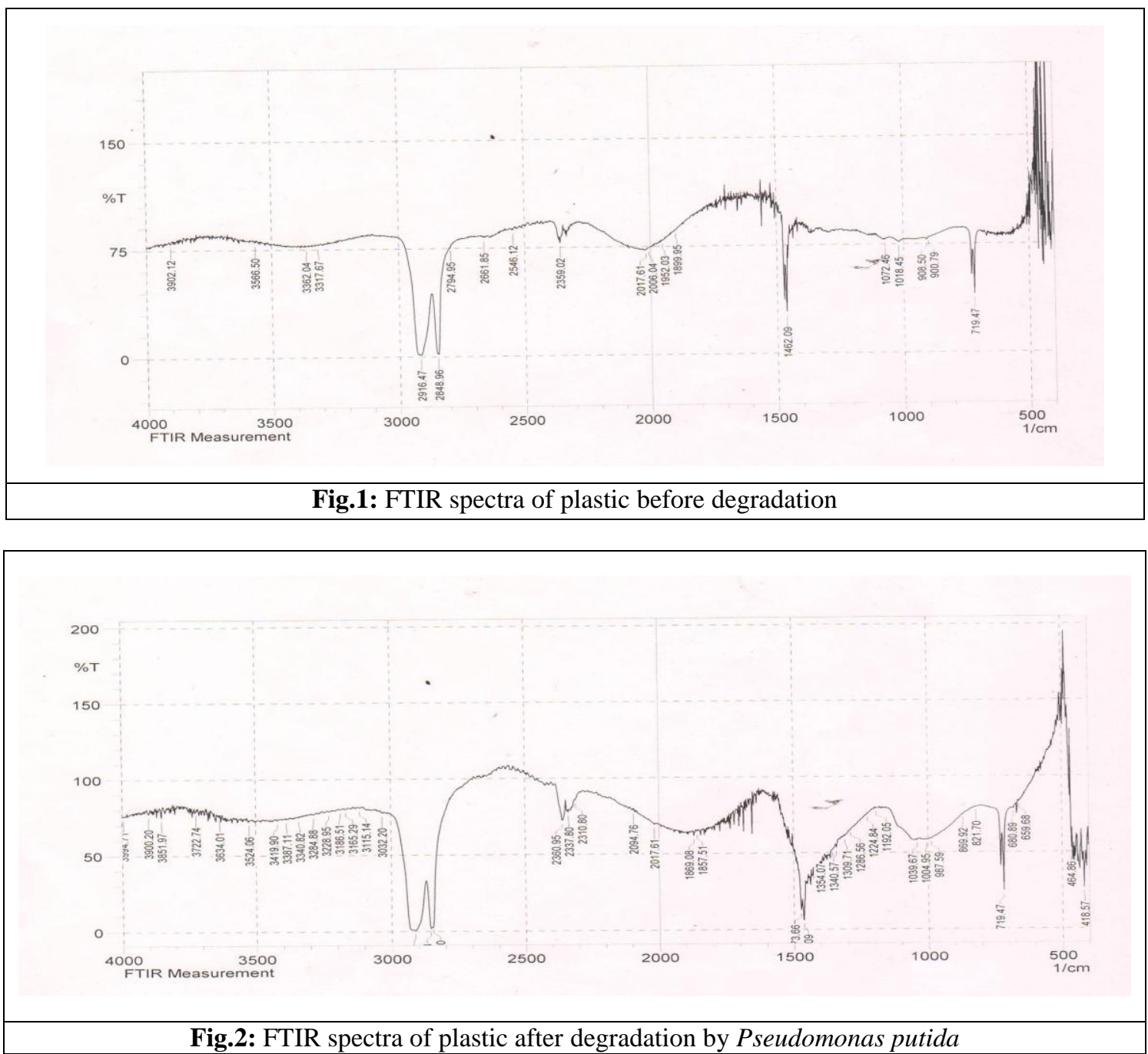

Figure 1 and 4 shows the degradation of plastic in synthetic media by bacteria. Plastic strips which were buried in soil were collected and added in synthetic medium containing bacterial species $P$. putida followed by Bacillus subtilis, Bacillus amylolyticus Bacillus firmus, Pseudomonas fluroscence and, which are found less plastic degrader as an extra decomposer, that soil combination was a simulation of landfills. Weight losses of polymer strips in medium could be assumed as an indicator of biodegradation in the landfills or natural environment. Soil microorganisms attacked the polymer strips.

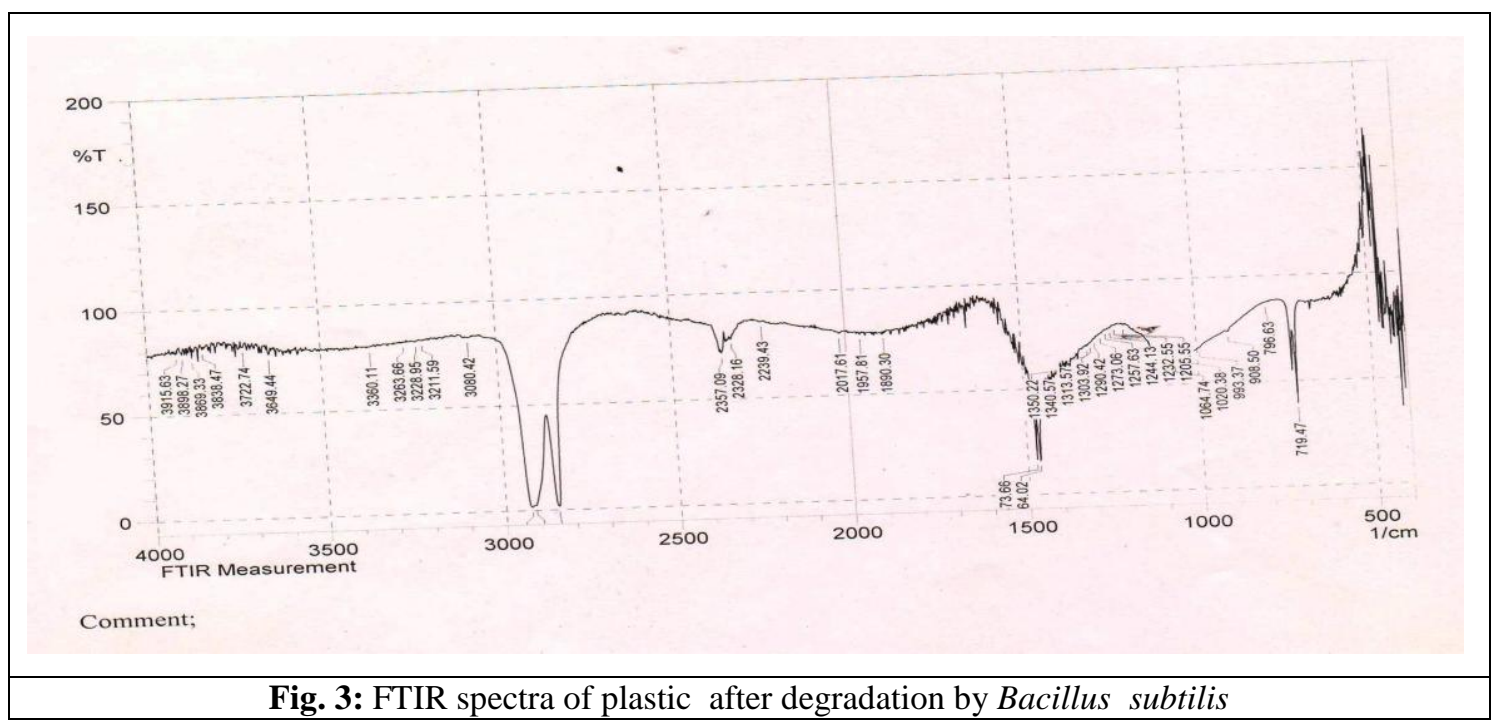


First of all, microorganisms were attracted to the plastic material as source of carbon. Microorganisms consumed plastic in the polymer matrix and caused a fracture in the LDPE chain. Because of the existence of maleic anhydride that made a chemical bond between LDPE and potato starch, degradation of potato starch caused a fracture in the polymer matrix and biodegradation of LDPE. FTIR exhibited some change in plastic, after degradation by bacteria. The highest decrease in spectrum was observed at $1500 \mathrm{~cm}-1$ derived from carbonyl groups of potato starches. This reduction confirmed the degradation of plastic in soil. Absorption band was between 1340- $1354 \mathrm{~cm} \mathrm{-1} \mathrm{because} \mathrm{of} \mathrm{the} \mathrm{weak} \mathrm{hydrogen} \mathrm{bond} \mathrm{between} \mathrm{starch} \mathrm{and} \mathrm{glycerol.} \mathrm{Absorption}$ band between 1340 and $1354 \mathrm{~cm} \mathrm{-1}$ was derived from C-O-H stretching bond. Alcohol absorption band was $987-1039 \mathrm{~cm}^{-1}$ and this indicated a fast degradation rate of carbon chain (Labuzek et al., 2004). This study has covered the major concerns about the natural and synthetic polymers, their types, uses and degradability also it has looked at the disposal methods and the standards used in assessing polymer degradation. Another area examined has been the biodegradation of plastics by the liquid culture method. It is clear that most recalcitrant polymers can be degraded to some extent in the appropriate environment at the right concentration.

\section{Conclusion}

A total of five bacterial strains capable of degrading plastic have been isolated from dumped soil. Most of them bacterial isolates are Gram positive and belong to genus Bacilli. It can be concluded that soil contains the potential candidates for bioremediation of plastic wastes.

The isolated microbes were native to the site of polyethylene disposal and might show some degradability in natural conditions, yet they also exhibited biodegradation in laboratory conditions on synthetic media. This gives some suggestion that these microbes can be used in both natural and artificial conditions for the purpose of degradation of polymers. Our knowledge, microbes cause greatest degradation of polythene and plastics. Among the bacteria, viz Pseudomonas putida followed by Bacillus subtilis, Bacillus amyloliticus Bacillus firmus, Pseudomonas fluroscence, having greater degradation ability. It is concluded that isolated strains are solely dependent on plastic for its carbon source. FTIR spectra also confirm the biodegradation of polymer as some chemical changes are seen in surface of polymer. Hence, the further attention is required from microbiologists for commercial degradation and eco-friendly polyethylene.

\section{Recommendations}

In the natural environment, different kinds of microorganisms play an important role in various steps involved in the degradation of synthetic polymers in general, and polyolefins in particular. Studying the synergism between those microorganisms will give insight for future efforts towards the biodegradation of these materials. In addition to screening soil microorganisms, isolating microorganisms from marine, petroleum waste and polymer dump site could lead to new unexplored strains, with superior performance. If one can characterize the genes responsible for the production of degrading enzymes and its regulation by using current genetic engineering tools, one can genetically modify the microorganisms and use them as a superbug for degrading the recalcitrant polyolefins.

\section{References}

[1]. Alexander M., Biodegradation of chemicals of environmental concern. Sci. 211,1981, 132-138.

[2]. Bollag, W.B., Jerzy Dec \& Bollag, J.M. (2000) Biodegradation \& encylopedia of microbiology. In Lederberg, J (ed.). Academic, New York. 461-471.

[3]. Chee JY, Yoga SS, Lau NS, Ling SC, Abed RMM and Sudesh KL (2010). Bacterially Produced Polyhydroxyalkanoate (PHA): Converting Renewable Resources into Bioplastics, edited by Mendez Vilas A. Applied Microbiology and Biotechnology.

[4]. Gu, J.D., Ford, T.E., Mitton, D.B. and Mitchel, R. (2000) Microbial corrosion of metals. W. Revie (Ed.), The Uhlig Corrosion Handbook (2nd Edition), Wiley, New York .915-927.

[5]. Kandler, O. and Weiss, N. (1986) Regular non-sporing Gram positive rods. In Bergey's Manual of Systematic Bacteriology ed. Krieg, N.R. and Holt, J.G. pp. 1209-1234. Baltimore: Williams \& Wilkins

[6]. Kathiresan, K., 2003. Polythene and plastics degrading microbes form mangrove soil. Rev. Biol.Trop., 51: 629-634.

[7]. Kim D. Y., H. Y. Rhee, Biodegradation of microbial and synthetic polyesters by fungi. Appl Microbiol Biotechnol. 61, 2003, 300308.

[8]. Kumar S., A. A. M. Hatha, K. S. Christi, Diversity and effectiveness of tropical mangrove soil microflora on the degradation of polythene carry bags. Int. J. Trop. Biol. 55 (3-4), 2007, 777-786.

[9]. Milstein, O., R. Gersonde, A. Huttermann, R. Frund, H. J. Feine, H. D. Ludermann, M. J. Chen, and J. J. Meister. 1994. Infrared and nuclear magnetic resonance evidence of degradation in thermoplastics based on forest products. J. Environ. Polym. Degrad. 2(2): 137-152.

[10]. $\quad$ Premraj R., M. Dobley, Biodegradation of Polymers, Ind. J. Biotechnol. 4, 2005, 186-193.

[11]. Shimao, M. (2001) biodegradation of plastics. Curr. Opin. Biotechnol, 12: 242-247.

[12]. Starnecker, A. and M. Menner, 1996. Assessment of biodegradability of plastics under stimulated composting conditions in a laboratory test system. International biodeterioration and Biodegradation, pp: 85-92.

[13]. Usha R, Sangeetha T and Palaniswamy M (2011). Screening of Polyethylene Degrading Microorganisms from Garbage Soil. Libyan Agricultural Research Center Journal International 2(4) 200-204. 